\title{
Uso de iSHAI y PGE00 para la monitorización de situaciones preconvectivas
}

https://doi.org/10.31978/639-19-010-0.035

\author{
Miguel Ángel Martínez Rubio' (mmartinezr@aemet.es) \\ Xavier Calbet Álvarez ${ }^{1}$ (xcalbeta@aemet.es)
}

${ }^{1}$ AEMET / Dirección de Producción e Infraestructuras

\begin{abstract}
RESUMEN
iSHAI es el producto del NWCSAF/GEO para el seguimiento en píxeles despejados de varios ingredientes claves en la convección; además, permite identificar las regiones donde el modelo numérico usado como entrada discrepa de la observación del satélite.

El programa PGE00 realiza en primer lugar la interpolación vertical, temporal y espacial de los perfiles de modelos numéricos a la proyección y hora de las imágenes de satélite; permitiendo generar para todos los píxeles los mismos campos que iSHAI. En segundo lugar, PGE00 puede ser usado para generar imágenes sintéticas de satélite con alto grado de realismo usando el modelo del ECMWF en niveles híbridos. Además de la comparación con imágenes reales, las imágenes sintéticas pueden ser utilizadas para generar nuevos desarrollos. Como ejemplo se presenta una RGB de masas de aire modificada en la que usando temperaturas de brillo reales y sintéticas se detecta mejor la intrusión de la estratosfera en el caso de estudio del 10 de agosto de 2016.
\end{abstract}

PALABRAS CLAVE: nowcasting; EUMETSAT; MSG; RTTOV; imágenes RGB; iSHAI; PGE00.

\section{INTRODUCCIÓN}

Dentro del paquete de software NWC SAF/GEO, iSHAI (imaging Satellite Humidity And Instability) realiza la estimación en píxeles despejados del contenido de agua precipitable en varias capas, varios índices de estabilidad, la temperatura de superficie y opcionalmente el total de ozono. Estos campos son útiles para la monitorización de varios ingredientes claves en la convección en pixeles libres de nube antes de que la convección tenga lugar.

Además, iSHAI permite identificar las regiones donde el modelo numérico usado como campo previo discrepa de la observación del satélite; para ello se escriben como salidas las diferencias entre los campos de iSHAI y los calculados a partir del modelo numérico. En la sección 2 se realiza una introducción a iSHAI y se muestran los campos en el caso de estudio del 10 de agosto de 2016. Todas las imágenes mostradas pertenecen a este caso de estudio; más información puede verse en (Martínez y CALbet, 2018) y (Martínez y Calbet, 2016), más imágenes y bucles están disponibles también en el hipervínculo.

En primer lugar, $\mathrm{PGE00} \mathrm{realiza} \mathrm{la} \mathrm{interpolación} \mathrm{4D} \mathrm{de} \mathrm{los} \mathrm{perfiles} \mathrm{de} \mathrm{modelos} \mathrm{numéricos} \mathrm{a} \mathrm{la} \mathrm{proyección} \mathrm{y} \mathrm{hora} \mathrm{de}$ las imágenes de satélite. En segundo lugar, PGE00 puede ser usado para generar imágenes sintéticas de satélite. En la sección 3 se realiza una introducción a PGE00 y se muestra cómo las salidas de iSHAI y PGE00 pueden ser utilizadas conjuntamente. También, se presentan ejemplos de comparación de imágenes sintéticas y reales.

En la sección 4 se realiza una introducción a los ficheros opcionales binarios y cómo tras la conversión de estos a formatos adecuados (netCDF y AREA McIDAS en caso de imágenes sintéticas) pueden ser utilizados para la explotación en 2D y 3D de forma interactiva. 
Además de la comparación con imágenes RGB reales, las imágenes sintéticas se pueden utilizar también para generar nuevos productos. En la sección 5 se presenta una modificación a la RGB de masas de aire en la que mediante la combinación de temperaturas de brillo (BT) reales y sintéticas se mejora la detección del núcleo frío en la intrusión de la estratosfera del caso de estudio al disminuir la contribución de la superficie.

A lo largo de este artículo se pretende demostrar cómo el uso combinado de las salidas de iSHAI y PGE00 puede ser utilizado de forma operativa para mejorar el nowcasting al permitir a los predictores chequear en tiempo real el modelo numérico frente a la observación del satélite. En la figura 1 puede verse un esquema de los procesos para la operación conjunta en tiempo real de iSHAI y PGE00.

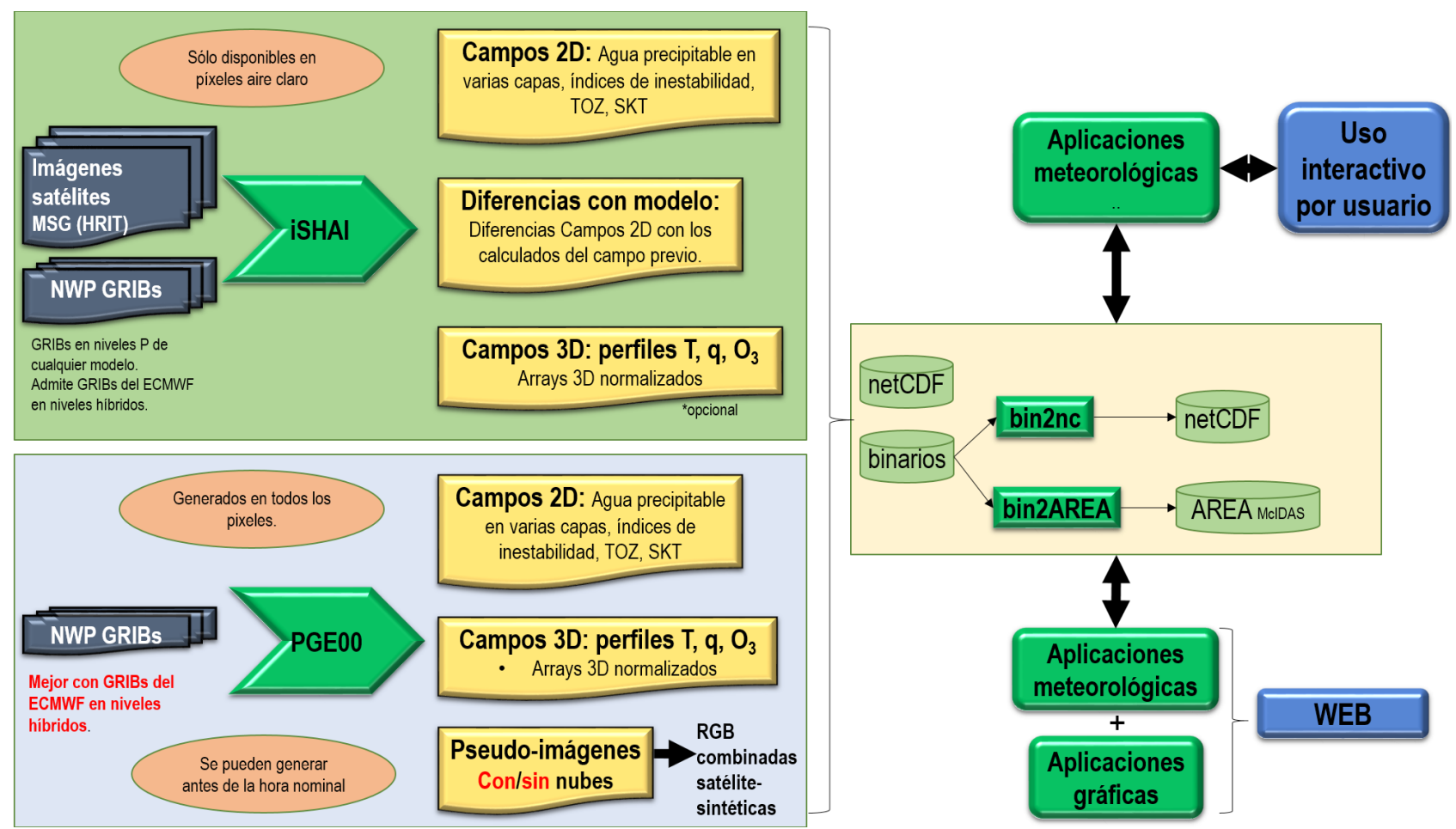

Figura 1. Esquema de procesos para la operación conjunta en tiempo real de ISHAI y PGE00.

\section{2. iSHAI}

En la figura 2 puede verse el esquema de uso de iSHAI con las principales entradas y salidas. iSHAI utiliza como entrada principal varios canales IR. Además, dado el bajo número de canales IR se usan los perfiles de temperatura y humedad previstos de un modelo numérico.

iSHAI es la combinación de un algoritmo estadístico seguido de un algoritmo de estimación óptima (physical retrieval). Para cada píxel despejado (o en cajas de $\mathrm{M} \times \mathrm{M}$ píxeles), iSHAI modifica los perfiles de temperatura y humedad interpolados a la hora y posición del píxel previstos por un modelo numérico en función de las diferencias entre las BT del satélite y las BT sintéticas. Como puede verse en la figura 3, en el primer paso se utiliza una regresión no lineal para construir el campo previo (First-Guess) a partir de los perfiles de temperatura y humedad de un modelo numérico (background $N W P$ ) interpolados a la hora y posición del píxel y las BT $_{\text {SATÉLITE }}$ corregidas de bias. En el segundo paso, se aplica un algoritmo de estimación óptima sobre componentes principales (EOF). Para acelerar más el cálculo, el segundo paso solo se realiza si la distancia entre las BT $\mathrm{BATÉLITE}_{\text {y }} \mathrm{BT}_{\mathrm{RTTOV}}$ en los canales no ventana es mayor que un umbral. En el cálculo de $\mathrm{BT}_{\text {RTTOv }} \mathrm{y}$ los jacobianos se utiliza el modelo de transferencia radiativa RTTOV del NWPSAF. 


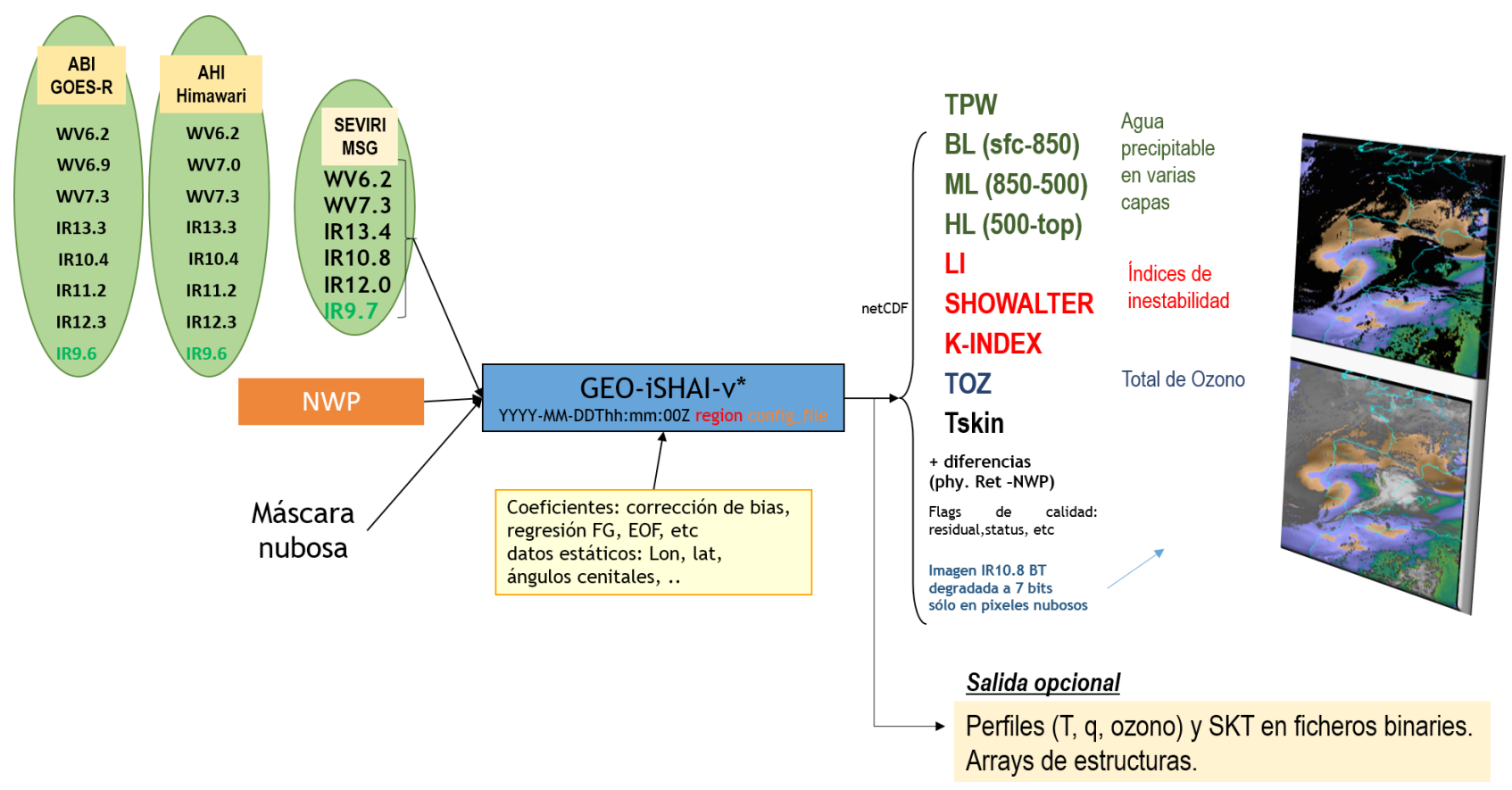

Figura 2. Esquema de entradas y salidas de iSHAI.

Finalmente, si es activada por el usuario la estimación del total de ozono (TOZ), se aplica una regresión no lineal para estimar el perfil de ozono usando como entradas: las $\mathrm{BT}_{\mathrm{SATÉ}}$ ITE corregidas de bias incluyendo ahora la $\mathrm{BT}_{\text {SATÉLITE }}$ en el canal cercano a $9,7 \mu \mathrm{m}$, los perfiles de temperatura y humedad estimados por iSHAI, el perfil de ozono del modelo numérico (background NWP) y la temperaturas de suelo (SKT). Con el perfil de ozono generado se calcula TOZ y la diferencia con el TOZ calculado desde el modelo numérico. Toda la información está disponible en el documento Algorithm Theoretical Basis Document (ATBD) de iSHAI disponible en la página web del NWCSAF. El algoritmo base fue proporcionado por Jun Li del CIMSS-U. Wisconsin en 2007 (Li et al., 1999) y es semejante al usado por la NOAA para el nuevo GOES-R (Li et al., 2010).

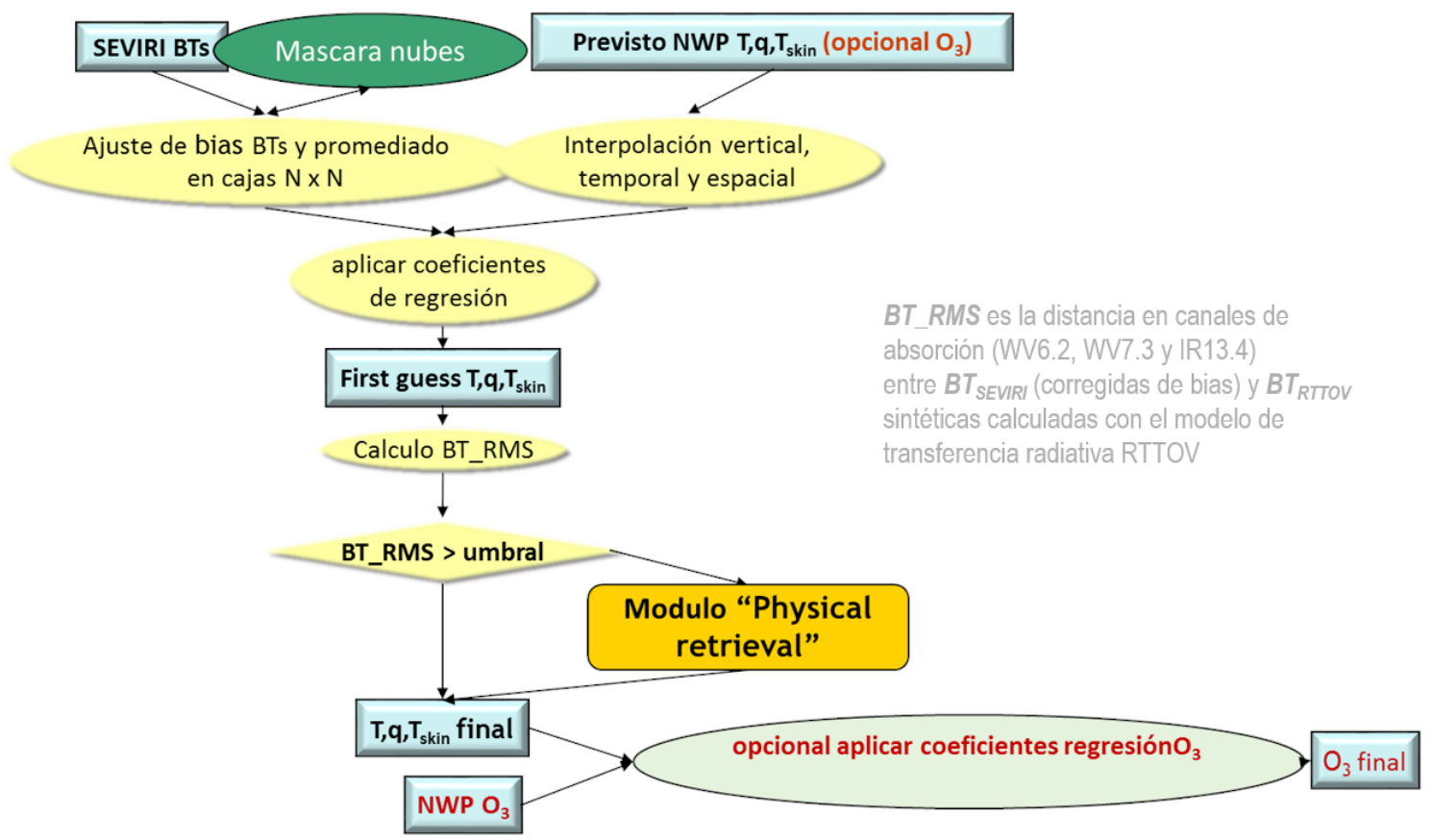

Figura 3. Diagrama de flujo de iSHAI. 
Aunque durante la ejecución de iSHAI se obtienen internamente los perfiles de temperatura, humedad y ozono en los 54 niveles de presión de los ficheros de coeficientes de RTTOV-11.2 (en los instrumentos tipo imagen son 54 niveles), el bajo número de canales IR hace aconsejable el calcular parámetros integrados en capas. iSHAI estima en píxeles libres de nubes el contenido de agua precipitable total (TPW), el agua precipitable en tres capas (BL: superficie a $850 \mathrm{hPa}$; ML: $850 \mathrm{hPa}$ a $500 \mathrm{hPa}, \mathrm{HL}$ : capa por encima de $500 \mathrm{hPa}$ ) y varios índices de inestabilidad [Liftex Index (LI), Showalter Index (SHW) y K-Index (KI)]. Además, desde la versión 2016, se generan la temperatura de superficie (Skin Temperature) y el total de ozono (TOZ); TOZ es opcional y solo se genera tras la activación por parte del usuario y si los ficheros GRIB proporcionados por el usuario contienen el perfil de ozono.

El resultado de iSHAI es un fichero en formato netCDF. Para complementar las salidas de iSHAI se añade al fichero netCDF de salida un campo con la BT en el canal IR10.8 en los píxeles cubiertos con nubes (detectadas por la máscara de nubes (CMa) del NWC SAF).

Es aconsejable utilizar como entrada a iSHAI el modelo numérico con la mejor resolución espacial, temporal y vertical posibles. iSHAI permite usar como entrada los ficheros GRIB en niveles de presión de cualquier modelo numérico que pueda ser usado como entrada al NWC SAF (modo P). En los ficheros GRIB del ECMWF en niveles de presión solo hay disponibles 25 niveles. Para mejorar la resolución vertical iSHAI permite usar en modo hybrid como entrada ficheros GRIB del ECMWF en coordenadas híbridas (137 niveles híbridos). Como ejemplo de las ventajas de la generación de iSHAI y PGE00 usando una configuración óptima, en este artículo se ha utilizado el modelo numérico del ECMWF con alta resolución temporal, vertical y espacial. Se han usado ficheros GRIB del ECMWF en niveles híbridos (137 niveles), cada hora desde el análisis al $t+24$ y con alta resolución espacial $0,125^{\circ} \times 0,125^{\circ}$. iSHAI ha sido reprocesado en $1 \times 1$ píxeles y procesando todos los píxeles también con la estimación óptima.

Como ejemplo de la automatización de los procesos descritos en la figura 1, las imágenes individuales han sido generadas con McIDAS-V ejecutado en modo batch usando el interface Python (en realidad Jython: Python sobre Java) y archivos con las configuraciones iniciales (bundles). Después, las imágenes individuales se han montado y animado usando ImageMagick mediante el uso scripts. En las páginas web de los hipervínculos las animaciones usan HAnis con ficheros de configuración actualizables de forma automática.

En la figura 4 se muestran las salidas del 10 de agosto de 2016 a las $12 \mathrm{Z}$. Se muestran con una paleta de colores los campos de iSHAI en los píxeles despejados y se superpone con paleta de grises la imagen IR en píxeles nubosos. Cuando se observan en bucles, el movimiento de las nubes (píxeles en gris) junto con el

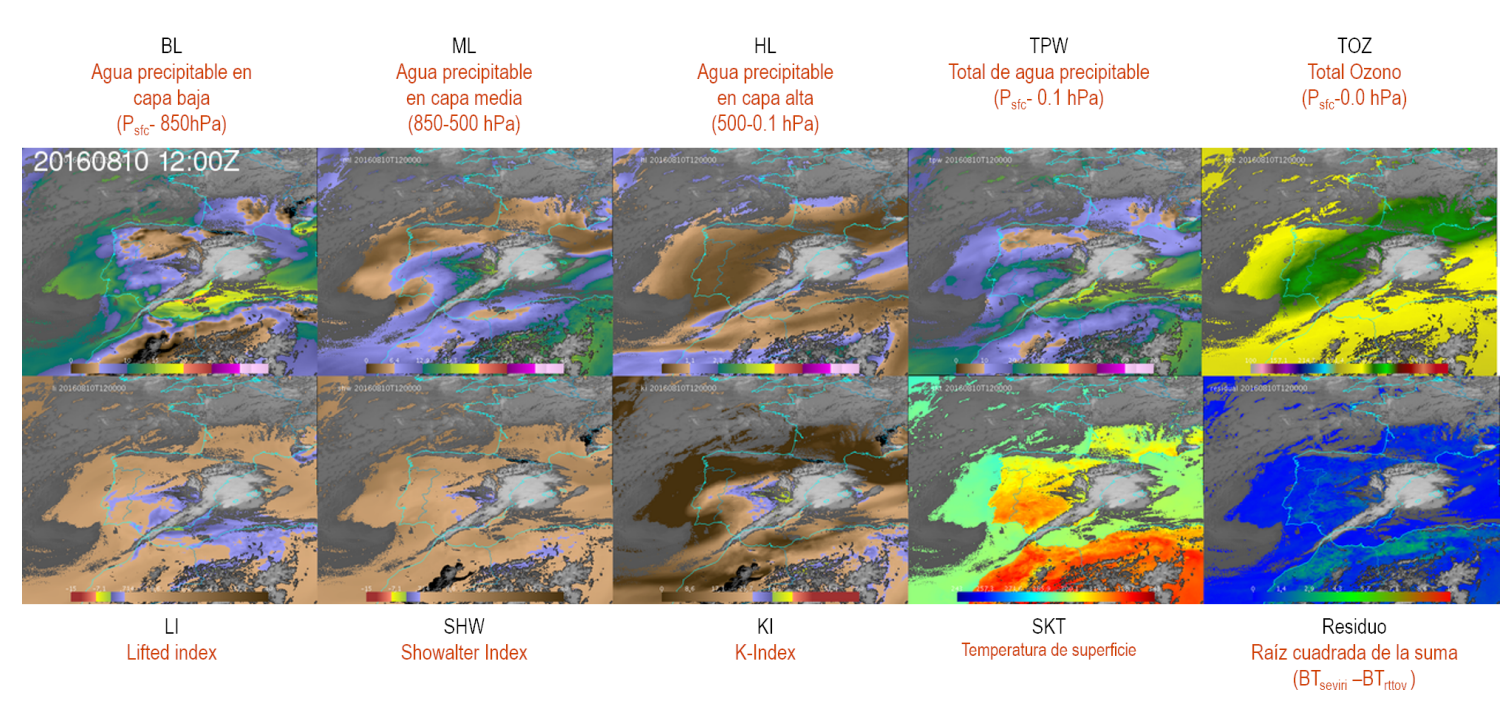

Figura 4. Ejemplo de salidas de iSHAI: agua precipitable en varias capas (BL, ML, HL y TPW); índices de inestabilidad (Lifted Index, Showalter y K-index); total de ozono, temperatura de superficie y residuo.

10 de agosto de 2016 a las $12 \mathrm{Z}$ usando previsto ECMWF $t+12$. 
movimiento de los campos (píxeles en color) permite una mejor identificación y seguimiento de las estructuras meteorológicas. En el hipervínculo puede verse la animación cada 15 minutos con los campos de iSHAI de la figura 4.

Además, iSHAI proporciona información en tiempo real sobre las regiones donde el modelo numérico previsto discrepa de los datos observados por el satélite en los campos de diferencia entre iSHAI y el modelo numérico; en la figura 5 se muestra un ejemplo; puede verse el bucle cada 15 minutos de los campos de la figura 5 en el hipervínculo.

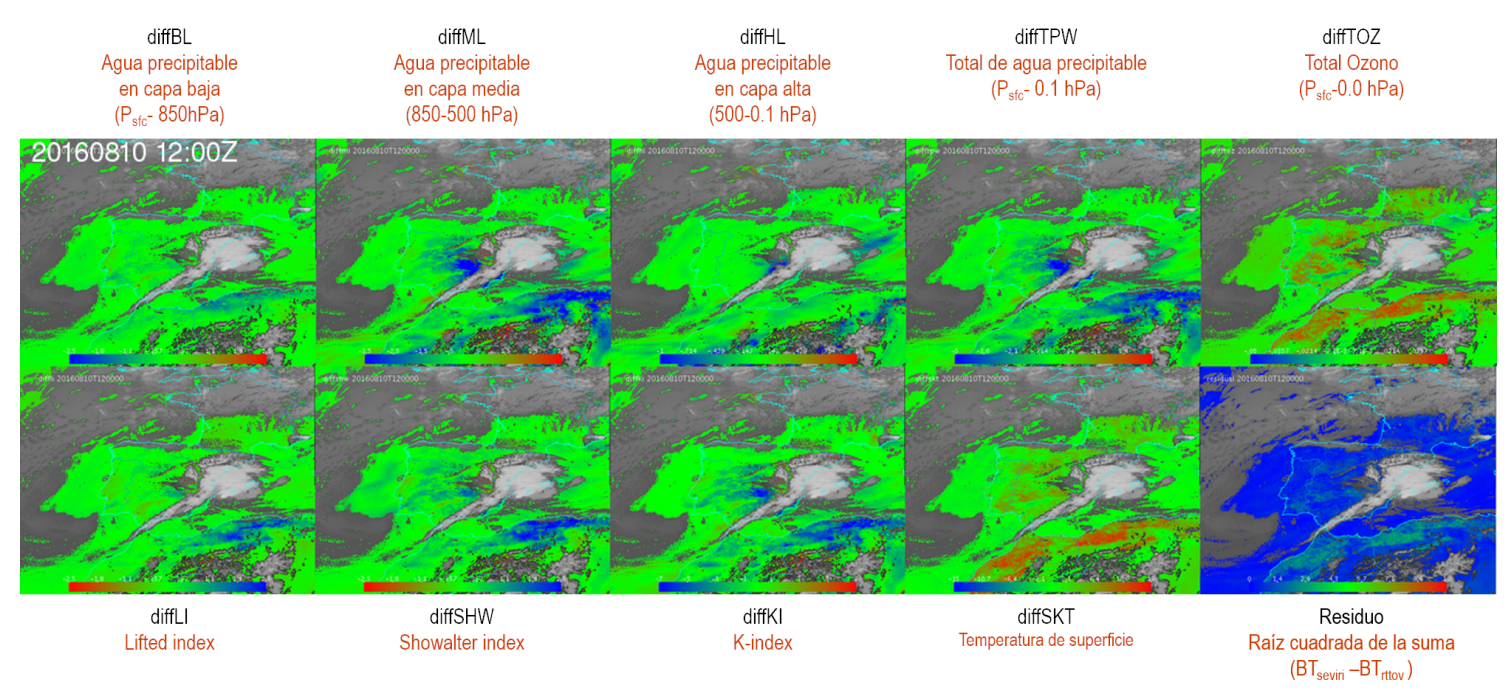

Figura 5. Ídem que en figura 4 pero campos de diferencia de iSHAI con modelo numérico.

iSHAI es generado unos pocos minutos después de la llegada de la imagen de satélite. Esto es clave ya que los análisis de los modelos numéricos no están disponibles hasta pasadas varias horas después de la observación. En la figura 6 puede verse como el predictor obtiene información de la sobreestimación en el campo ML del previsto a $t+12$ horas del ECMWF pocos minutos después de la observación; esto permitiría no ampliar la zona de avisos por tormentas. Hasta pasadas varias horas no tendría la confirmación con el análisis de que el contenido de agua precipitable en el $t+12$ estaba sobreestimado. Desde 2014, el ECMWF tiende a una sobreestimación en ML en casos convectivos. En (MARTínEZ, 2015) hay dos casos de estudio con PGE13 (nombre anterior de iSHAI) en los que el ECMWF presenta una infraestimación.

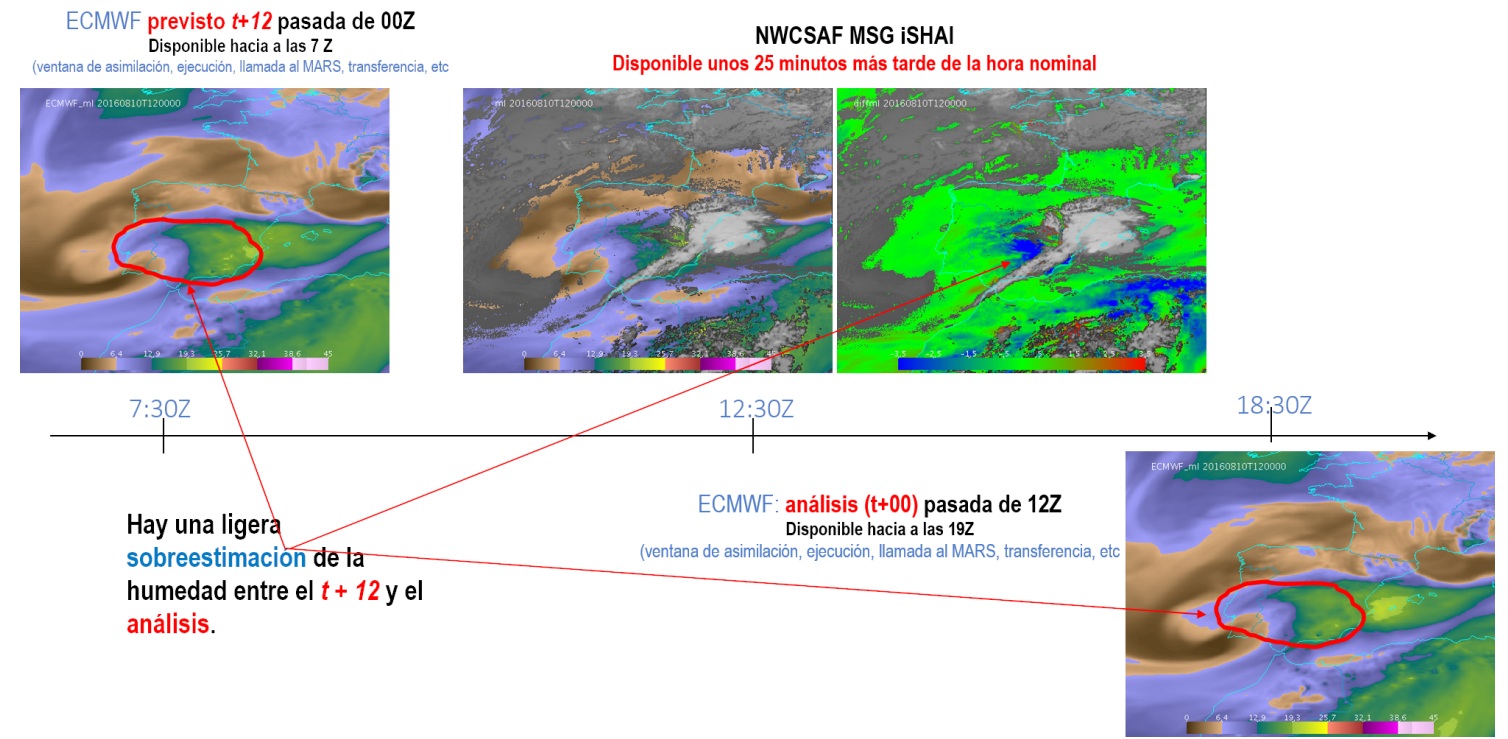

Figura 6. Hora de disponibilidad de campos ML iSHAI y PGE00. 10 de agosto de 2016 a las $12 \mathrm{Z}$. 


\section{PGE00}

El conjunto de programas PGE00 no forma parte del software del NWC SAF y es por ahora una herramienta interna de AEMET para desarrollos en el NWC SAF. PGE00 se empezó a desarrollar para la generación de coeficientes de corrección de los bias entre las BT $\mathrm{BATÉLITE}_{\text {y }} \mathrm{BT}_{\mathrm{RTTOV}}$ en píxeles sin nubes. También se utilizó para la generación de datasets de entrenamiento y validación. Después, se le añadió la funcionalidad de generación de BT sintéticas tanto en aire claro como con nubes usando RTTOV; en las primeras versiones (RTTOV-9.2 a RTTOV-11.2) la simulación de las nubes era pobre pues se realizaba especificando únicamente el nivel y fracción de nube del tope nuboso. En la última versión de PGE00 con RTTOV-12.1, se ha añadido la generación de imágenes sintéticas tanto en el visible como el infrarrojo utilizando los perfiles de nubosidad y de contenido de agua de nube usando como entrada ficheros GRIB del ECMWF en niveles híbridos. Esto permite la simulación con un mayor grado de realismo de las nubes en canales visibles e infrarrojos como puede verse en las figuras $9 \mathrm{y} 11$.

\section{1. PGE00 como interpolador 4D (vertical, temporal y espacial)}

En primer lugar, PGE00 realiza la interpolación 4D de los perfiles de los modelos numéricos a regiones en proyección satélite. En la figura 7 está descrito el proceso de interpolación 4D para ficheros GRIB del ECMWF en niveles híbridos. PGE00 abre y lee los ficheros GRIB anterior y posterior más cercanos a la hora de la imagen; después realiza la interpolación vertical de los perfiles en los GRIB anterior y posterior en los puntos de la rejilla del modelo numérico. En la interpolación vertical se realiza la interpolación/extrapolación desde los perfiles en niveles híbridos a perfiles en niveles de presión con la densidad que se desee; por defecto a los 54 niveles de presión de RTTOV. Después, se realiza la interpolación temporal a la hora elegida por el usuario. Finalmente, se realiza la interpolación espacial a los puntos de la imagen de satélite. Para acelerar el proceso, editando el fichero de configuración de PGE00, se puede elegir en hacer la interpolación espacial sobre todos los píxeles o sobre un conjunto de puntos prefijado (uso de un fichero máscara) o solo sobre píxeles no nubosos (máscara de nubes de NWC SAF) o saltarla y generar en la rejilla de los puntos del modelo.

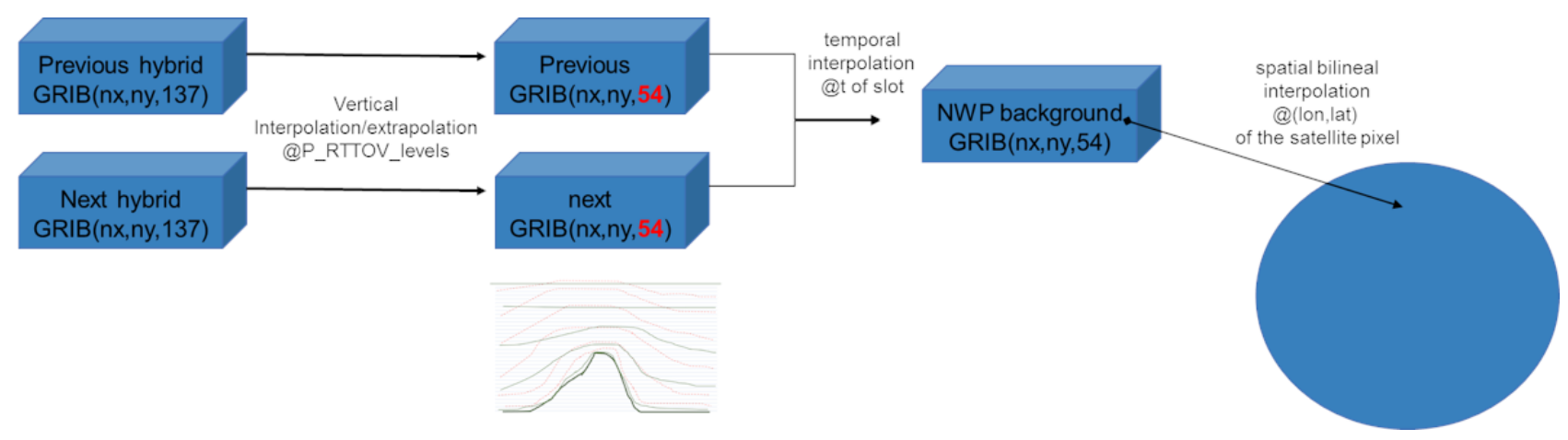

Figura 7. Proceso de interpolación 4D para ficheros GRIB del ECMWF en niveles híbridos.

Con los perfiles interpolados la primera utilidad de PGE00 es generar las mismas salidas que iSHAI en todos los píxeles para una comparación directa entre las salidas de iSHAI y de los modelos numéricos. Estos campos se pueden pregenerar a la llegada de los ficheros GRIB y tener los campos de PGE00 antes de la recepción de las imágenes.

En la figura 8 puede verse una composición de las salidas de iSHAI y PGE00 mostrando la presencia de humedad en el cuadrante sureste peninsular y una intrusión de la estratosfera (valores altos de TOZ). Puede verse como el patrón espacial de los campos de PGE00 BL y ML complementan a los de iSHAI en las áreas 
cubiertas de nubes. Los campos de iSHAI proporcionan la posición de las estructuras nubosas dentro de los patrones del campo de agua precipitable. La mayor potencia de la combinación se obtiene al ver las animaciones cada 15 minutos (ver bucle); en el bucle la alta resolución temporal y espacial permite apreciar detalles como el movimiento en el valle del Guadalquivir del agua precipitable en niveles bajos y cómo penetra usando los pasos con menor altura. Por estas razones es conveniente usar como entrada modelos numéricos con alta resolución temporal y espacial.

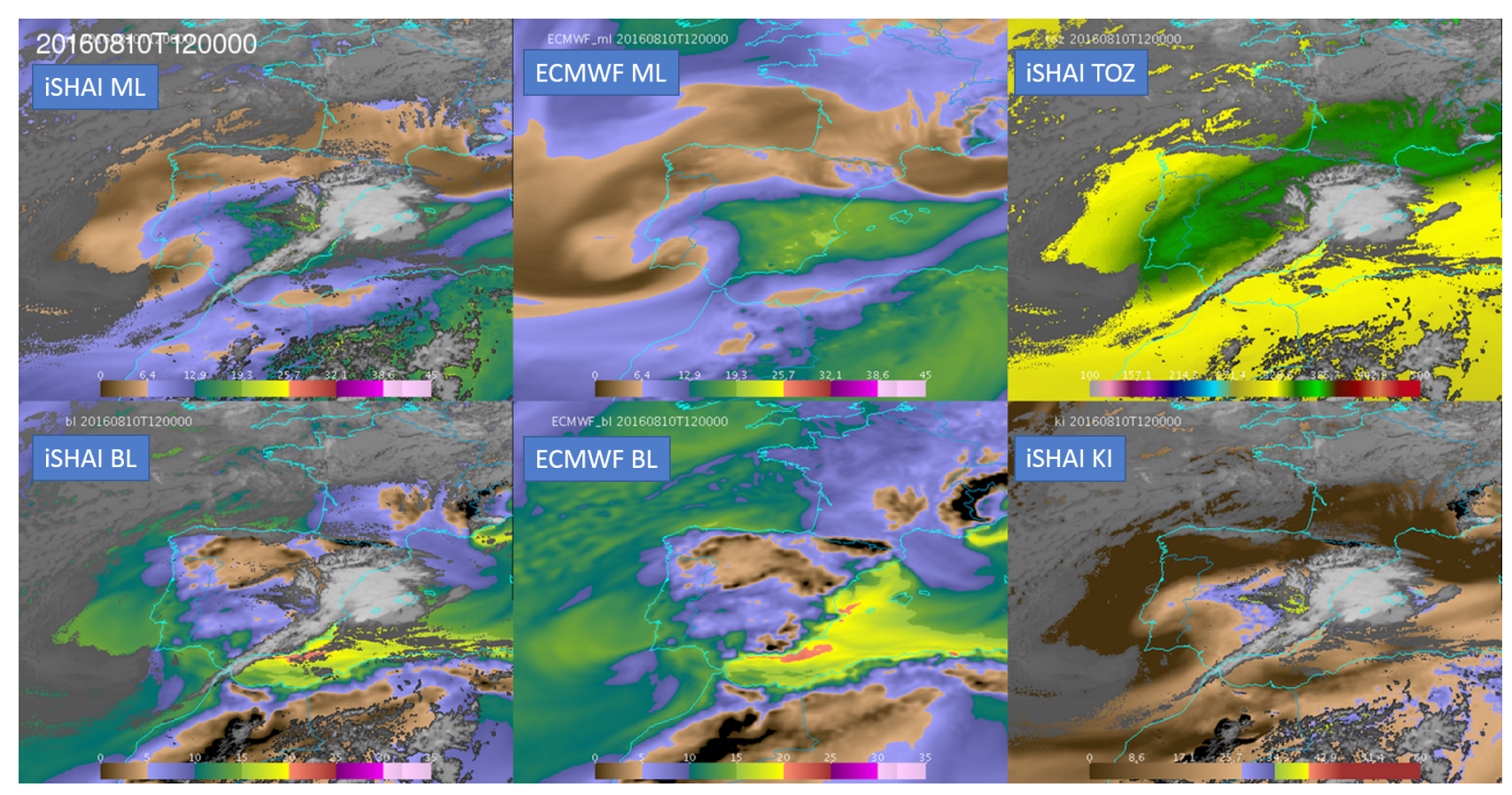

Figura 8. Ejemplo de uso conjunto de iSHAI y PGE00: 10 de agosto de 201612 Z.

\subsection{PGE00 como generador de imágenes de satélite sintéticas de alta calidad}

De forma opcional, ejecutando PGE00 con las opciones correspondientes (nombre del instrumento, satélite, canales, procesar con nubes o sin nubes, activar radiación solar) se pueden generar imágenes de satélite sintéticas de alta calidad. PGE00 con RTTOV-12.1 permite simular cualquier satélite de los que se disponga coeficientes de RTTOV. RTTOV-12.1 dispone de los coeficientes para simular nubes y aerosoles tanto en canales visibles como IR para prácticamente todos los satélites meteorológicos (actuales o futuros como MTG).

Para la simulación de las nubes con alta calidad usando GRIB ECMWF en niveles híbridos además de los perfiles $\left(T, q \mathrm{y} \mathrm{O}_{3}\right)$ se utilizan en la llamada a $R T T O V \_$direct los perfiles de nubosidad y contenido de agua de nube (CC, CLWC, CIWC). Para obtener resultados más realistas se usan en la llamada a RTTOV los atlas de emisividad y BRDF de RTTOV.

Las radiancias sintéticas se pueden usar para la creación de imágenes RGB sintéticas que pueden ser mostradas de forma conjunta con imágenes reales o para nuevos desarrollos. Al comparar con imágenes reales se pueden descubrir las regiones donde el modelo discrepa con la realidad. En la figura 9 puede verse la comparación de imágenes RGB natural normalizada real y sintética de MSG; (ver bucle en hipervínculo). Como las RGB sintéticas pueden ser generadas con anterioridad pueden ser usadas para comparar diferentes pasadas de modelos numéricos. También pueden ser generadas las RGB sintéticas con canales visibles durante la noche usando un ángulo cenital solar por defecto para los canales visibles. 

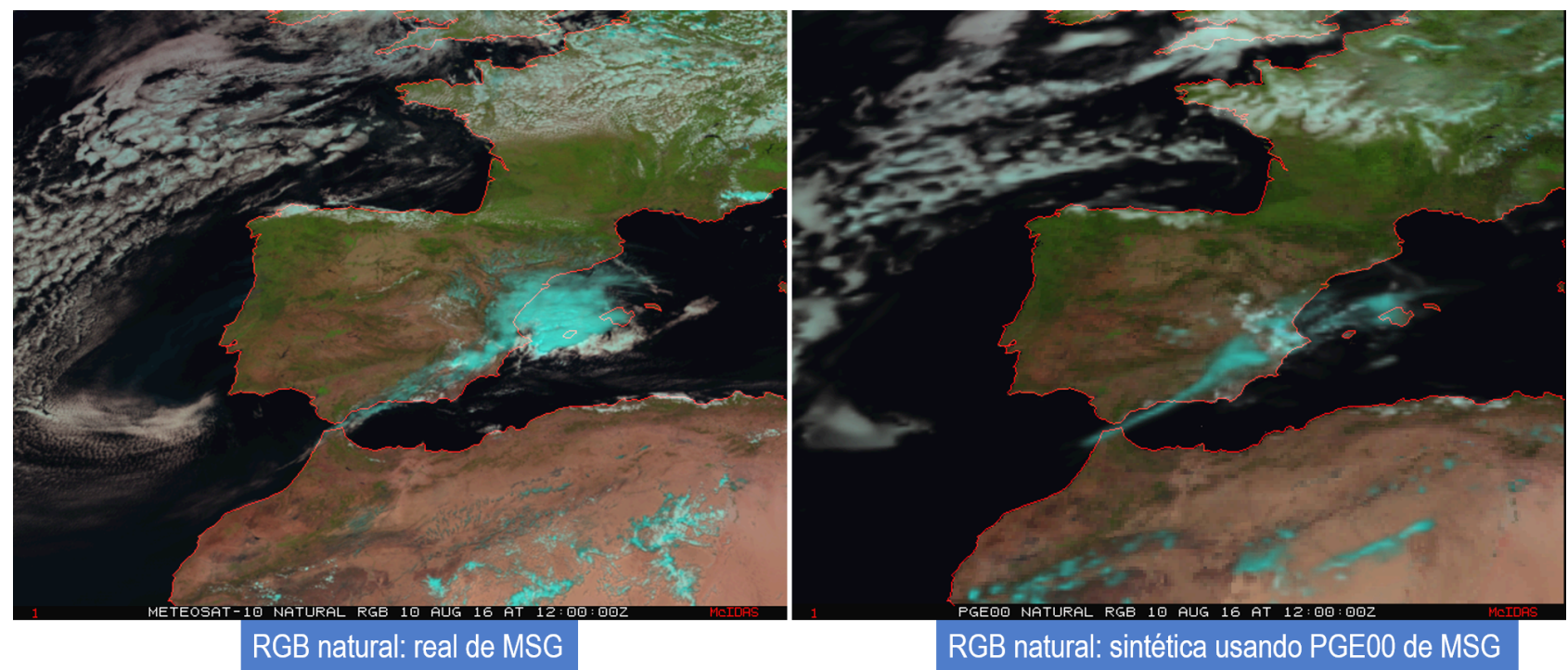

Figura 9. Imágenes RGB natural normalizada real y sintética de MSG. 10 de agosto de 201612 Z.

\section{2.a. Imágenes RGB sintéticas en tiempo real en Intranet}

Desde 2017 están disponibles en Intranet en el hipervínculo las imágenes RGB sintéticas de masas de aire y natural de las pasadas $00 \mathrm{Z}$ y $12 \mathrm{Z}$ del ECMWF de los 3 últimos días generadas con GRIB ECMWF niveles híbridos con resolución $0,125^{\circ} \times 0,125^{\circ}$ cada 1 hora entre $[t+00, t+24]$ tras la recepción de los ficheros GRIB del ECMWF. Más detalles en Sección 4.1.b.

\section{FICHEROS BINARIOS OPCIONALES Y CONVERSIÓN A FICHEROS netCDF Y AREA MCIDAS-X}

iSHAI y PGE00 son programas configurables editando los ficheros de configuración. En iSHAI existe la opción de activar la escritura en ficheros binarios de los perfiles estimados. En PGE00 y los ficheros opcionales de iSHAI la salida se hace en formato binario escribiendo los arrays de estructuras con los perfiles y los campos disponibles (como las BT sintéticas) en cada píxel. Como los ficheros binarios no se pueden usar directamente en ninguna aplicación se han creado programas para la conversión desde binario a formatos adecuados para la explotación interactiva por el usuario en 2D y 3D con alguna herramienta meteorológica.

En los resultados mostrados en este artículo se han usado programas IDL para la conversión a netCDF o ficheros AREA McIDAS que se pueden usar con las herramientas de libre distribución McIDAS-V y/o IDV. El código IDL se podría migrar a C o Fortran o Python. Como alternativa a IDL podría usarse también la versión libre GDL (GNU Data Language).

\section{1.a. Conversión de los ficheros binarios a formato NetCDF}

Se ha diseñado la estructura NetCDF, los nombres (standard_name) de las variables y los atributos para que sean CF compliant y para que además se puedan utilizar en McIDAS-V con todas la funcionalidades. Probablemente, estos ficheros NetCDF puedan ser usados también con otras aplicaciones (Unidata Python AWIPS, librería Python de NCAR/UCAR de UCAR/UNIDATA). La geolocalización se hace usando la longitud y latitud de los ficheros longitud y latitud del directorio $\$ S A F N W C / t m p$ para la región usada. 
Un problema al generar cortes verticales con variables como la temperatura y la humedad es el que el rango de valores entre niveles bajos y altos es muy amplio. Para evitar este hándicap una solución es escribir en los netCDF arrays 3D de $T$ y $q$ normalizados en cada nivel de presión; estos se pueden usar para detectar la presencia de anomalías frías/calientes y/o húmedas/secas usando una paleta de colores adecuada. Los arrays normalizados se pueden usar en McIDAS-V para realizar después cortes verticales como los que se pueden ver en la figura 10. Se ha usado como normalización la resta del valor medio y la división por la desviación estándar en cada nivel del análisis del caso de estudio. En el bucle puede apreciarse (dada la alta resolución de los GRIB del ECMWF usados) cómo los colores azulados correspondientes a la penetración del aire frío en altura se mueven hasta alcanzar la vertical de la región húmeda (colores verdes) y es cuando se dispara la convección.

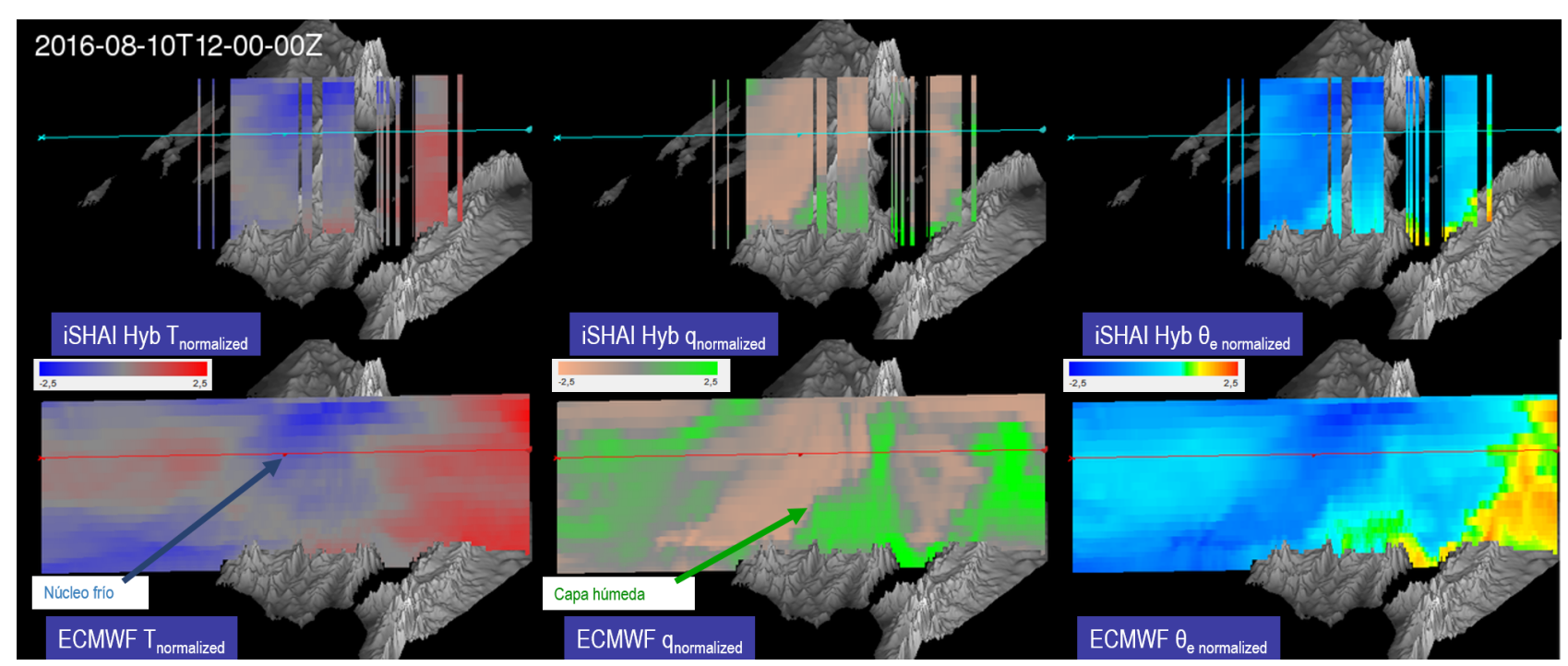

Figura 10. Ejemplo de generación de cortes verticales con McIDAS-V. 10 de agosto de 2016 12Z.

\section{1. b. Conversión reflectancias y BT sintéticas de los ficheros binarios a AREA McIDAS-X}

Se ha usado un programa IDL para convertir desde los ficheros binarios a formato AREA McIDAS tipo MSG con los 12 canales a la vez. La conversión se realiza invirtiendo el proceso de la calibración de las imágenes reales; las BT y reflectancias se convierten primero a radiancias y después a cuentas (RAW) usando los parámetros de calibración de MSG reales. Los ficheros AREA McIDAS-X sintéticos pueden ser usados con McIDAS-X (o McIDAS-V o IDV) y usar los mismos script para generar las imágenes RGB sintéticas que los usados con los AREA MSG reales. El resultado puede verse en las figuras 9 y 11.

Para acelerar el proceso (debido a no disponer de una máquina dedicada) en la cadena demostración en tiempo real de la Sección 3.2.a. se genera una imagen cada hora en $2 \times 2$ (McIDAS-X amplía con MAG=2). Debido a tener que realizar la llamada al MARS para cada GRIB y el envío por ectrans del ECMWF a AEMET la generación de todas las imágenes de una pasada tarda unas 4 horas desde la ejecución del modelo. El procesamiento de cada fichero tarda unos 30 minutos y se realiza con una cadena Python que: ejecuta PGE00, realiza la conversión a AREA McIDAS, ejecuta McIDAS-X para la generación de imágenes RGB, utiliza rsync para actualizar en el servidor de Intranet las imágenes y las animaciones, etc.

En PGE00 se generan los 12 canales MSG tanto con nubes como sin nubes y los perfiles de temperatura, humedad y ozono, etc. por lo que se podrían generar infinidad de productos más. Además, una vez generados los ficheros netCDF y AREA McIDAS, se podrían servir mediante dataset McIDAS ADDE para que los usuarios pudieran tener acceso en tiempo real. 


\section{RGB DE MASAS DE AIRE COMBINADA (REAL-SINTÉTICA)}

Una de las deficiencias de la RGB de masas de aire es que, en verano, en las horas centrales del día las altas temperaturas no permiten detectar la presencia de intrusiones de la estratosfera. Puede verse en la figura 11 como tanto en la RGB de masas de aire real como en la RGB sintética sobre la península ibérica y en el desierto del Sahara aparecen colores muy oscuros y se aprecia mal la intrusión de la estratosfera con altos valores de TOZ (véanse figuras 4 u 8).
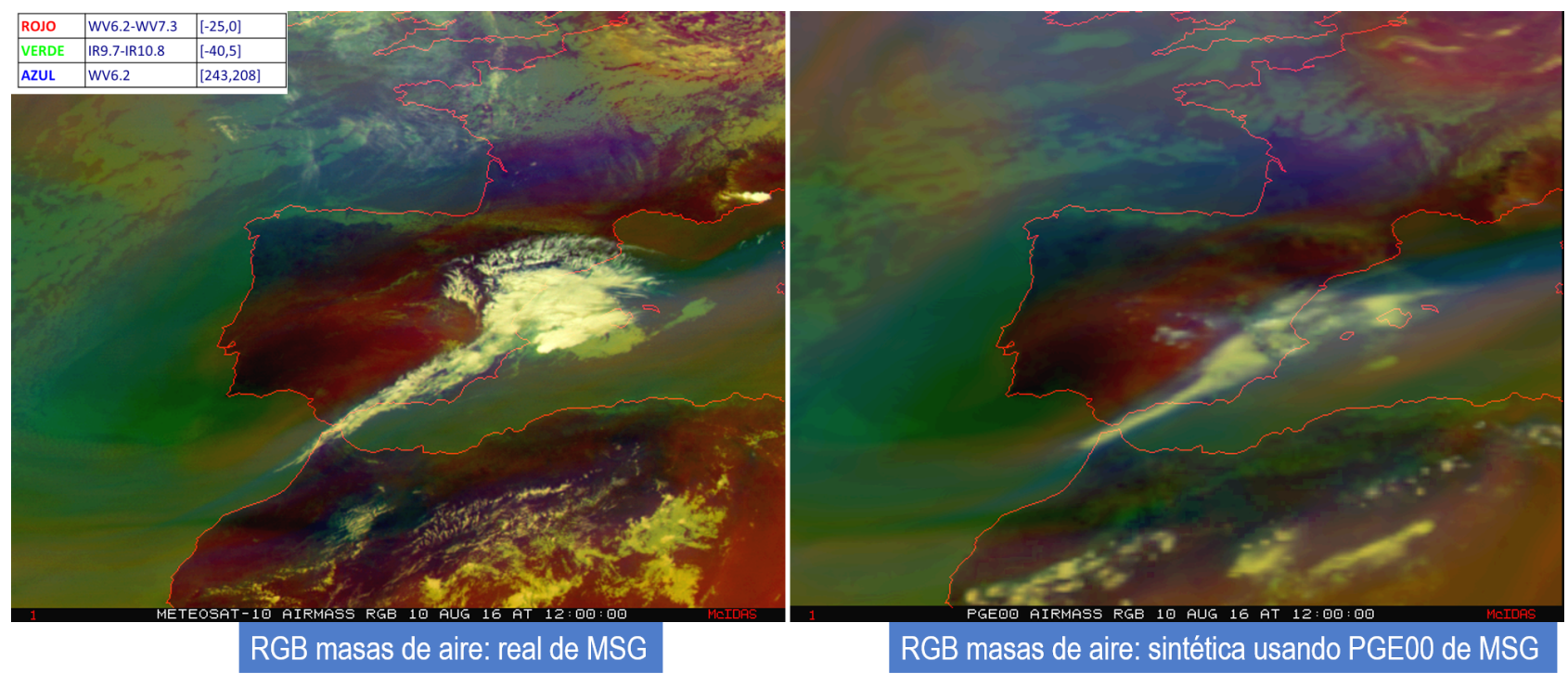

Figura 11. Imágenes RGB de masas de aire real y sintética de MSG. 10 de agosto de $201612 \mathrm{Z}$.

En la RGB de masas de aire se utiliza el canal IR9.7 en el haz verde $\left(\mathrm{BT}_{\mathrm{IR} 9.7}-\mathrm{BT}_{\mathrm{IR} 10.8}\right)$ por su sensibilidad al contenido de ozono. Como puede verse en la figura 12, la función de peso del canal IR9.7 tiene un máximo en niveles altos debido al ozono pero presenta una contribución no nula en niveles bajos y en la superficie; por esta razón se trata de eliminar esta contribución en niveles bajos restando la BT del canal IR10.8. Pero en verano con suelos muy calientes está diferencia no es suficiente para realizar la corrección.

Como un ejemplo de las posibilidades de PGE00 para la mejora de las RGB, se han generado también las BT sintéticas en aire claro usando los perfiles de $T$ y $q$ del modelo en cada píxel y el valor medio del perfil de

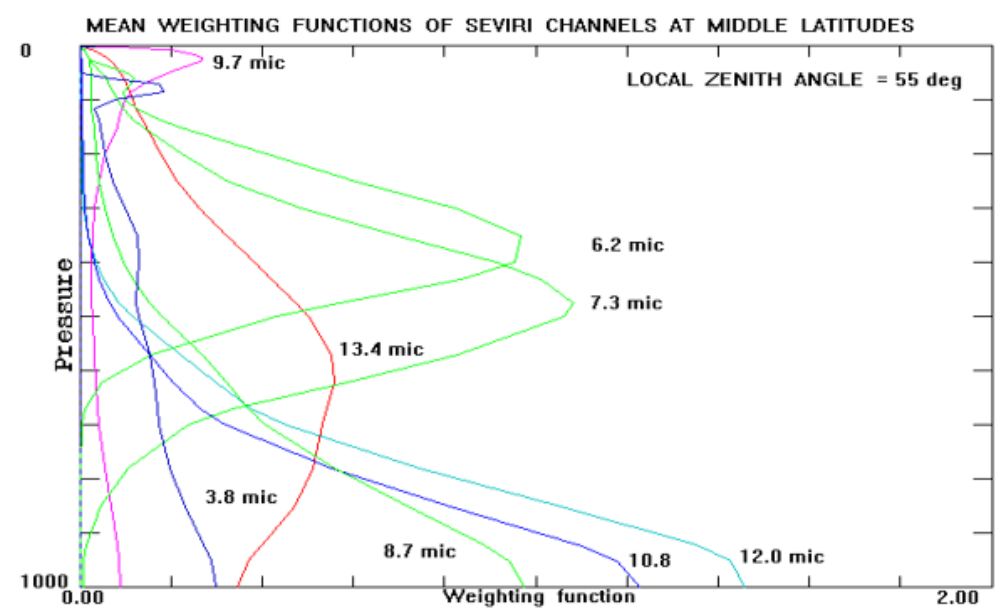

Figura 12. Funciones de peso de los canales SEVIRI de MSG. 


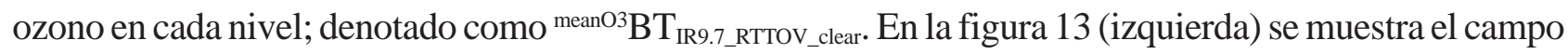

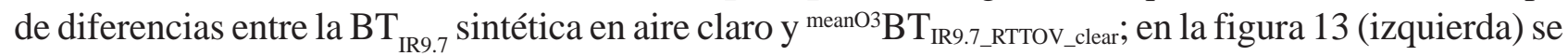
detecta claramente en tonos oscuros la presencia de la región con altos valores de TOZ.

En la imagen de la derecha de la figura 13 se ha cambiado en la RGB de masas de aire la componente verde por $\left(\mathrm{BT}_{\mathrm{IR} 9.7 \_R T T O V_{-} \text {clear }}-{ }^{\text {meanO3O3 }} \mathrm{BT}_{\text {IR9.7_RTTOV_clear }}\right)$. Esta RGB de masas de aire modificada sí muestra en colores oscuros y rojizos la presencia de la región con altos valores de TOZ en píxeles y además no se ve la superficie.

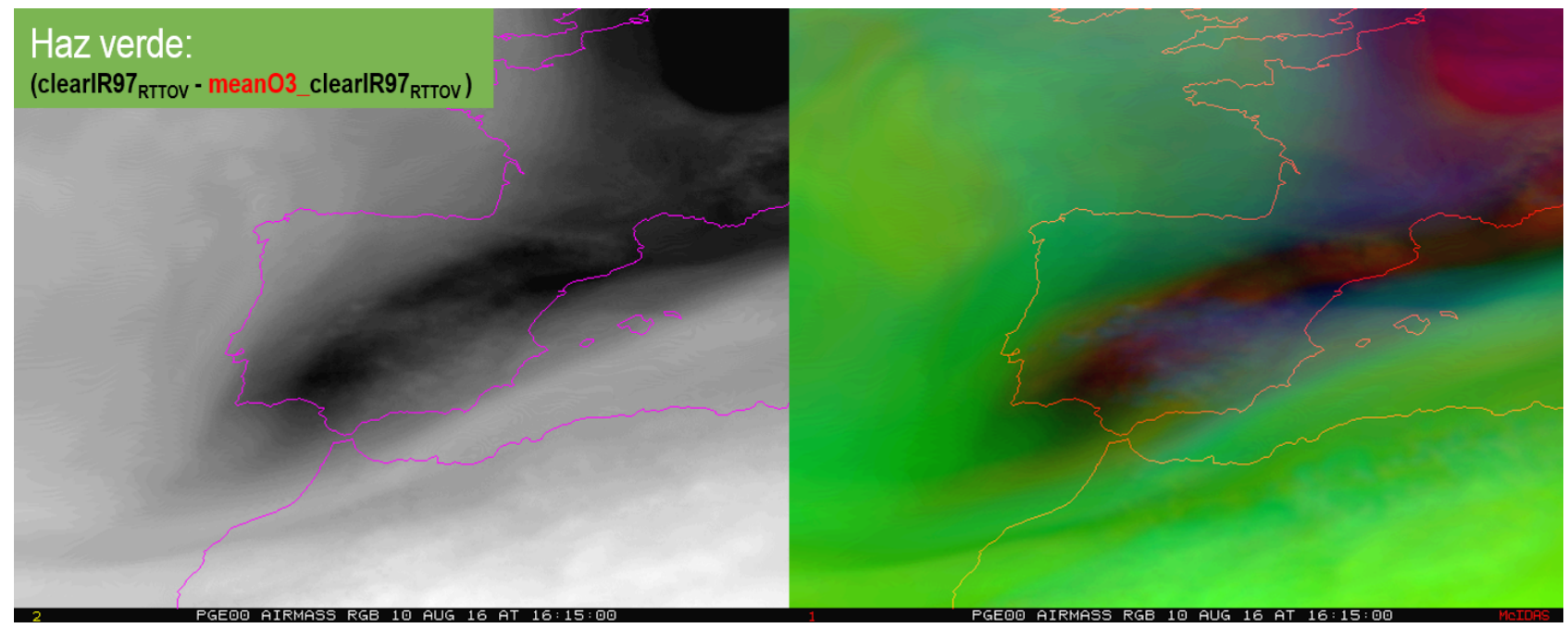

Figura 13. Ejemplo de RGB de masas de aire combinada usando BT sintéticas.

Cuando se utilizan en la RGB las BT reales, es necesario además corregir la diferencia entre la $\mathrm{BT}_{\mathrm{RTTOv}}$ y la BT $_{\text {SATÉLITE }}$ en el canal IR9.7 para corregir las diferencias entre la temperatura de superficie real y del modelo. Tras varios intentos la mejor corrección se ha conseguido usando una regresión de la diferencia entre las BT real y RTTOV entre el canal IR10.8 e IR9.7. La componente verde propuesta para imágenes reales es:

$$
\left(\mathrm{BT}_{\mathrm{IR} 9.7}-{ }^{\text {meanO3 }} \mathrm{BT}_{\mathrm{IR} 9.7 \_R T T O V_{c} \text { clear }}\right)-\left(0,54 *\left(\mathrm{BT}_{\mathrm{IR} 10.8}-{ }^{\text {meanO3 }} \mathrm{BT}_{\mathrm{IR} 10.8 \_R T T O V \_c l e a r}\right)+0,18\right) \text {. }
$$

Como puede verse en la figura 14 (bucle) se detecta perfectamente la presencia de la región con altos valores de TOZ en la región con píxeles en colores oscuros y rojizos aunque ahora se intuye la superficie.

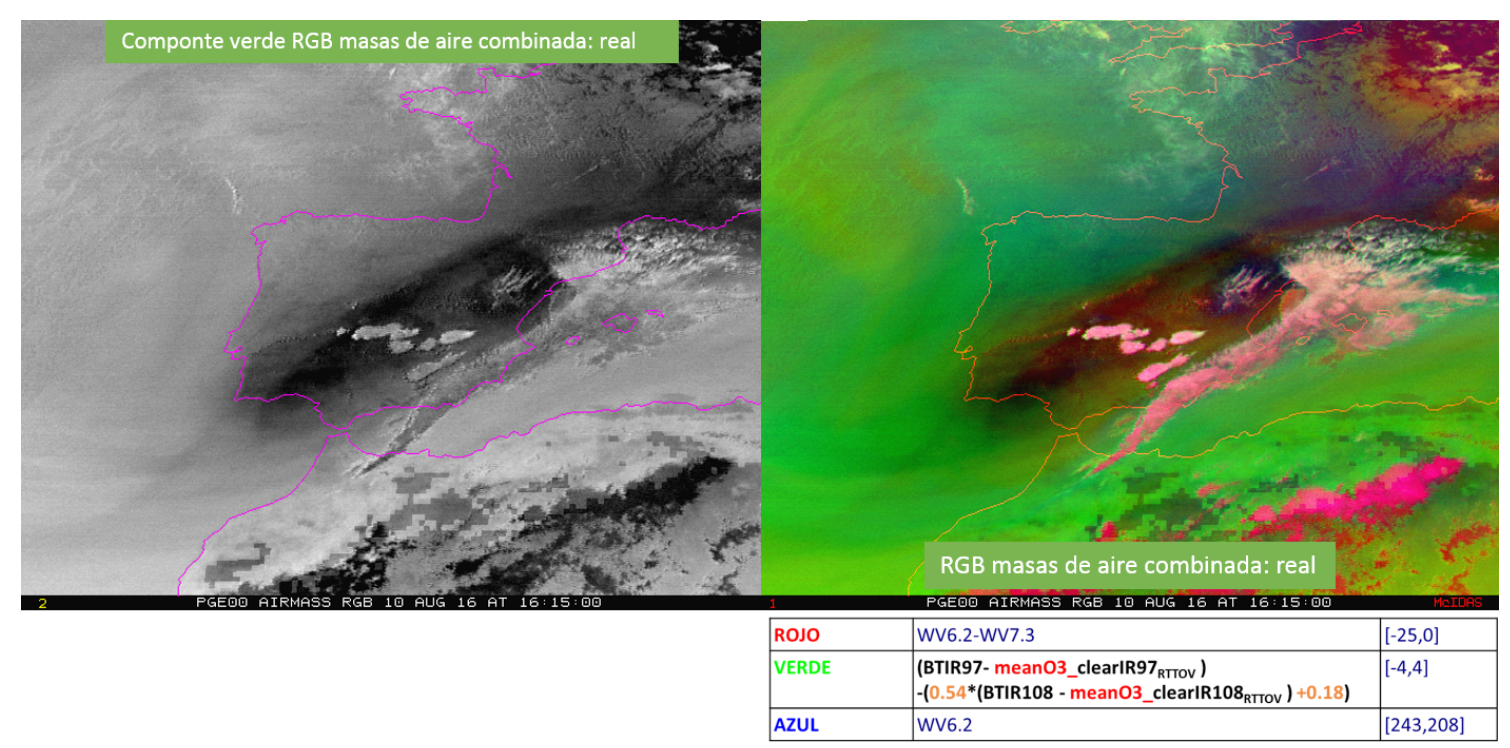

Figura 14. Ejemplo de RGB de masas de aire combinada (real-sintética con perfil medio de ozono). 


\section{CONCLUSIONES}

El uso combinado de iSHAI y PGE00 mejora la monitorización de ingredientes claves en situaciones preconvectivas y la monitorización de las desviaciones del modelo respecto a la observación realizada por el satélite.

Se ha mostrado que el uso de modelos numéricos con alta resolución vertical, temporal y espacial (como el ECMWF cada 1 hora en niveles híbridos) en programas como iSHAI y PGE00 genera productos de alta calidad.

Las imágenes RGB sintéticas tienen un gran potencial al permitir la comparación de la nubosidad en las imágenes de satélite con las previstas por el modelo. La RGB de masas de aire propuesta sería una solución para evitar la deficiencia de la RGB de masas de aire en los meses de verano; aunque se deberían hacer estudios adicionales.

La posterior conversión a formatos de salida que sean compatibles con las herramientas como McIDAS-V puede facilitar enormemente las tareas de predicción; permitiendo por una parte el procesamiento por lotes para pregeneración de salidas gráficas para páginas web y por otra parte el uso interactivo para la exploración $2 \mathrm{D}$ y $3 \mathrm{D}$ para casos y regiones de especial interés. De cara a una futura puesta en operación en AEMET casi todos los procesos que compondrían la cadena operativa de la figura 1 están desarrollados o existe un prototipo.

\section{REFERENCIAS}

LI, J. et al., 2010. NOAA-NESDIS ATBD for ABI Legacy Atmospheric Moisture Profile, Legacy Atmospheric Temperature Profile, Total Precipitable Water, and Derived Atmospheric Stability Indices. En línea en: http://www.goes-r.gov/products/ATBDs/baseline/Sounding_LAP_v2.0_no_color.pdf.

Li, Z., Li, J., Menzel, W. P., Schmit, T. J., Nelson, J. P. y Ackerman, S. A., 2008. GOES sounding improvement and application to severe storm nowcasting. Geophysical Research Letters, 34, L03806, doi:10.1029/2007GL032797. En línea en: https://www.ssec.wisc.edu/ junl/.

Li, J. y HuANG, H.-L, 1999. Retrieval of atmospheric profiles from satellite sounder measurements by use of the discrepancy principle. Appl. Optics, Vol. 38, No. 6, 916-923. En línea en: https://www.ssec.wisc.edu/ junl/.

Martínez, M. A. y CALbet, X., 2018. iSHAI and PGE00 as key tools in pre-convection. 2018 Convection Working Group Workshop in Ljubljana, Slovenia. En línea en: pptx o pdf con bucles en NWCSAF web.

Martínez, M. A. y CALBEt, X., 2016. NWCSAF/GEO clear air product version 2016. Evolution to the MTG era. Proceedings of the 2016 EUMETSAT Meteorological Satellite Data User's Conference, Darmstadt, Germany. En línea en: https://www.ssec.wisc.edu/ junl/.

Martínez, M. A., 2015: MSG Clear Air Products. Evolution to the MTG era. En línea en: link. 